\title{
Real Strategy as a Foundation Document to Guarantee Quality Management and Assurance in the "Haxhi Zeka" University
}

\author{
Shqiponja Nallbani PhD(cand.) \\ University "Haxhi Zeka"- Pejë, \\ shqiponja.nallbani@unhz.eu
}

Doi:10.5901/ajis.2014.v3n2p333

\section{Abstract}

Currently, the institutions of the government of the Republic of Kosovo have taken concrete actions to decentralize the Higher Education by opening new universities in the regional centers and by setting the conditions for a competitive intercollegiate environment where the true principles and a condition for a contemporary institution will, above all, be the academic quality management assurance. For this vision, the relevant institutions have issued a series of strategic and legal documents which will provide for an acceptable legal and academic base for all higher education providers and with the proper view of the situation and current needs, they will be drafting and implementing strategic documents. Initially, these documents will guarantee the mechanisms for providing necessary information on all weaknesses, risks, opportunities and priorities of the segments for the university academic development, analyzing these up to the adoption of managerial actions which will ultimately result in a strategic document that guarantees quality and quality only. Although established two years earlier, 'Haxhi Zeka' University has made progress in organizing academic activities but has not yet taken any serious and substantive steps to mobilize all segments within the university and on the basis of shared responsibilities to draft and implement the document with normative and academic force to assure the management of the university's quality. It is considered that the academic quality is related to the well composition of the variables of competencies in teaching and students learning, intercollegiate cooperation, scientific research and adopting programs according to the market requirements and conditions both inside and outside the country. These objectives may be achieved only by specialized managers who are prepared for changes, respectively with a modern manager profile.

Keywords: Higher education, quality, management, university, strategy

\section{Introduction}

Currently, the quality is in the center of all activities of the universities adopting and seeing it as a culture of the development of the system of the overall quality management. There is no doubt that each Higher Education providers aims to manage the process in compliance to the national and international standards and best practices especially in regards to continuing trends in the European arena of Higher Education and Bologna Guidelines.

In the modern academic world, the process of quality and management assurance is undoubtedly one of the key points which makes them functional and worthy for an honest competition in the market. But, what is the situation in the Republic of Kosovo and what is being done to set this critical segment and make it stabile in its place? What is happening and what is the true engagement of authorized institutions to have this obligation operational in the newly established public universities.

Almost all Higher Education institutions, only in the formal plan have issued unclear documents that attempt to regulate the quality management assurance. But it has been concluded that this segment is not sufficiently functioning in practice, in terms of transparency and self assessing culture. Above all, the studied strategic documents are formally identical and do not contain the specifics that the respective providers have. Moreover, there are no human resources, managers, educated, qualified and prepared within the offices or centers, to have the process of quality management assurance be legally possible on the functional academic plan and to be acceptable by the responsible subjects. Often, the concerns were raised regarding the true lack of quality in this level of education and continue to be raised by the foreign experts who are offering assistance or presented in the expert capacities from the accreditation Agency of Kosovo. The assessment reports, respectively the recommendations offer data on how to build a self assessment system which may guarantee the quality assurance and self improvement.

"Haxhi Zeka" University as new Higher Education institution was established and operational based on a typical legal framework same as with other sister universities in the region. Governing and managing structures of the institutions 
have the basis and the sufficient legal space to draft strategic documents or regulation to guarantee the quality management and assurance in all its necessary steps. What has been done so far though is not sufficient, therefore this document contains an initial document that sets the academic normative and functional framework in Haxhi Zeka University.

\section{Legal Basis for Quality Management Assurance in Kosovo}

The Republic of Kosovo is clearly following the path that makes the providers of the higher education gradually similar to the European Universities which are the main strength in creating the 'Europe of knowledge'. For this reason, our country has issued several important documents to recommend and oblige all stakeholders that during the development of their scientific and academic activities, to implement them. Almost the entire current legislation is in support of the Strategy for the development of Higher Education 2005-2015, a document which has a mission and clear objectives [The strategy for the Development of Higher Education 2005 - 2015, MEST Prishtina 2004 mission "The development of an efficient system of higher education that will contribute to increase the wellbeing of the Kosovar society by offering high quality education and research, with equal opportunities for all, in accordance with the values of freedom, democracy and diversity." Link http://www.masht-gov.net/advCms/documents/MINISTRIA_E_ARSIMIT_Strategjia_e AL fund.pdf me datën 11.11.2013]. The institutional determination is that this strategy is a document that obligates all Higher Education Institutions to implement the principles of Bologna and Lisbon and more specifically in article 4 it requests to promote and support academic policies which continually provide for the revitalization of education programs and texts and to finance the establishment of new public institutions and provide the necessary assistance to the private institutions, drafting policies to improve the conditions and possibilities to study, teach and carry scientific research inside and outside the country, enhance the quality of intensive study accredited programs according to the market requirements, increasing the quality of work to provide for a competing system of higher education in region and abroad [The strategy for the Development of Higher Education 2005 - 2015, MEST Prishtina 2004 mission "The development of an efficient system of higher education that will contribute to increase the wellbeing of the Kosovar society by offering high quality education and research, with equal opportunities for all, in accordance with the values of freedom, democracy and diversity." link http://www.masht-gov.net/advCms/documents/MINISTRIA_E_ARSIMIT_Strategjia_e_AL_fund.pdf me datën 11.11.2013].

The law on Higher Education is the sole legal act based on which was created the legal basis for regulating, functioning, financing, providing the quality in higher education in compliance with European standards as well as the role of state and society in development of higher education in the Republic of Kosovo [Law No.04/L-037 On Higher Education In The Republic Kosovo, linkhttp://www.masht-gov.net/advCms/documents/ministria_e_arsimit_strategjia_e_al _fund.pdf me datën 11.11.2013].

Based on this Law, the providers of Higher Education are obliged to engage in order to assure internal quality which includes the formal evaluation of processes by which the provider assures

Itself that his offer (whether of programs or of services) meets standards which correspond to

European best practice and show continuous improvement [Law No.04/L-037 On Higher Education In The Republic Kosovo, linkhttp://www.masht-gov.net/advCms/documents/ministria_e_arsimit_strategjia_e_al_fund.pdf me datën 11.11.2013]. In order that the provisions of the aforementioned law are implemented in a more detailed manner and the assignment of duties and responsibilities from the authorized institutional segments in function of the quality management and assurance, the Minister of MEST has issued several Administrative regulation such as No 02/2013 on the Accreditation of the institutions of Higher Education in the Republic of Kosovo [MEST Administrative Order, No. 02/2013 on the Accreditations of the Institutions of Higher Education in the Republic of Kosovo ], and the Regulation No. 14/2013 on the Teachers performance evaluations [MEST Administrative Order No. 14/2013 on the Teachers Performance Evaluations ]. These regulations clearly set the duties and the responsibilities of the Higher Education institutions, schoolmasters, students and other independent agencies all in function of quality management assurance and guaranteeing. It was concluded that the Republic of Kosovo has the sufficient legal basis that each provider at the higher education is obliged that as soon as possible to regulate its academic activity in accordance to the academic nature that the academic programs have with individual legal acts such as the Statute, internal regulation and adequate strategies which can truly be implemented.

This shows that the state institutions have taken the responsibilities to establish the institutions of the Higher Education and simultaneously enable them to receive resources in order not to only accomplish their mission but to accomplish it in an excellent manner which would then consequently enable them to compete with higher education systems of other continents. 
Therefore not only Europe but the entire world is becoming a 'society of knowledge' and the Lisbon tractate, the creation of the European fields of Higher Education and Research, jointly with all the efforts of states, should be reviewed continuously in order to meet the challenges it represent. These must be viewed as important engagements for the universities since they contribute to the innovation through teaching and learning via research and knowledge sharing.

\section{Budget and Recourses}

In order to have the possibility to make an adequate planning of the activities for quality assurance (reviews, internal/external assessment, etc.) there should be enough budget shared for the academic unit and also for the actual implementation of its activities. Failure to do this will result in interrupted activities and measures in the middle, resulting with the loss of resources [Manual for Drafting the Framework for Quality in Higher Education, drafted via the project for Support and Development of the Structures for Quality Assurance in the Private Institutions for Higher Education in Kosovo-Bucharest, Cork, Gratz, Prishtina, Salzburg, 2011].

It must be emphasized that within MEST and Public Universities there is no foreseen budgetary code for budget allocation to cover the financial cost of quality management and assurance. Unfortunately even in the budget of 'Haxhi Zeka' University there is no allocation of means or any budgetary sum linked to this segment which makes us skeptical on a true and serious determination of its management to deal with this issue in a proper level with an academic culture.

\section{What should a strategic document of 'Haxhi Zeka' University, contain for quality management and assurance.}

Haxhi Zeka University with the aim to manage and assure quality must issue a dynamic strategic document that should determine the internal organizational structure, the responsibilities of the academic and administrative level that would efficiently accomplish their assigned tasks and duties.

The document is based on structural specifics of Haxhi Zeka University and as such it has the full support in the Statute in power and clearly determines the policies, procedure, structures and quality initiatives that should be created, developed, implemented, monitored and evaluated through an integrated approach set as follows:

Quality assurance to be focused on academic issues, teaching and learning and linked closely to those services which directly support the students such as the library, student services and carrier center.

Quality management's objectives should be the effective development, implementation and monitoring of policies and procedures as well as the quality of administrative and service sections

Policies, procedures, process and quality initiatives must focus on continues improvement through regular self assessment with objectives, standards or performance criteria, progress review and overall assessment. In the institutional and unit level, the academic and administrative leaders should identify the priorities and articulate the weaknesses and strengths and design plans and actions which would be modulated in a wider level, distributed and used actively.

It is the final time when the University must strongly start promoting a modern academic culture in which every faculty, department and individual is involved and sees the quality improvement at the latest instance, as an individual and collective responsibility. All interested parties must be notified for relevant issues linked to the quality in order to ensure that everyone is involved in developing a culture of quality in which the achievements are recognized and awarded whilst the performance and lack of it are managed effectively. All other data and analytic materials as well as the evidences must be used with caution in order to ensure that trials and decisions are open, transparent and are clearly supported with relevant information.

The university must guarantee in the document of quality management and assurance the regular and sustainable maintenance of an internal structure of the quality which is suitable and above all adequate for the purpose [European qualification framework for lifelong learning -published by the European Community Commission / Brussels, 8.7.2005 SEC (2005) 957, according to this document the competencies include i) cognitive competencies that include the use of theories and concepts as well as other unofficial forms gained from experience; ii) functional competencies (skillstechnical skills) which a person must be able to carry when in an working environment, social activity or a learning process. iii) Personal competencies which include the ways how to behave in a specific situation and iv) ethical competencies that include personal and professional values.]. This includes the governing subjects of the university who shall exercise their competencies and strengthen the role as follows:

$\checkmark$ The University's Steering Council as the principle governing body of the University has the authorization to 
approve the strategic plan where the quality management and assurance becomes a vital part of the university and society and as such it also bears the final responsibility in this area.

$\checkmark$ Rector is the authorized institution and as such must lead the quality process and is responsible to the steering council. Legally the Rector is responsible to draft the Action plan for quality self assessment in the University level (Quality Self-Assessment Action Plan) which links to the priorities in different areas. This plan should be delivered for approval to the Steering Council and Senate and must be over sighted by the Quality Center and Academic Development.

$\checkmark$ The establishment and the functioning of the Committee for quality management and assurance that would be comprised of the Rector, Vice Rector, General Secretary and the executive adviser which would draft, implement and monitor the action plan for quality assessment and self assessment. (CQMA prepares the annual report for the Senate and the Steering Committee for critical review)

$\checkmark$ Technical support is provided by the official for quality assurance. The Committee shall meet at least 4 times in the first and the second year, during the academic year.

$\checkmark$ Strengthening and functioning of quality assurance teams in each faculty/center, administration and support services that have the responsibility for the self assessment process and the implementation of the action plans for quality assurance in their fields.

- The faculty teams would be comprised of the Dean, Vice Deans, representatives of the academic staff and students and an external member (stakeholder) selected by the faculty council with one year mandate which may be extended.

- The team of the administration and support services is comprised of the officials responsible in the services.

$\checkmark$ All shall regularly report to the center for Quality Management and Assurance on the progress. They meet at least twice a year.

$\Rightarrow$ The center of the office for Quality Assurance must be the basic structure with authorization to coordinate the operation and activities to ensure quality and ensures that information is shared. The culture of the quality to be promoted via a set of communication tools.

$\Rightarrow$ Academic and administrative staff, students and stakeholders are encouraged to actively participate in developing assessment modules as well as in the operation and reviewing of the same.

In order to develop a culture of quality, the university must use a set of internal mechanisms which must be connected with external mechanisms in an appropriate manner including but not limited to the following points:

\& Development and approval of curricula must be done in strict compliance to the instructions. The National accreditation and assessment council approves and ri -assess the study programs and the students are evaluated in accordance to the evaluations instruction.

\& The quality of teaching and learning must be preserved and developed through an annual scheme of teaching observations, annual assessment made by the students, the individual assessments of staff and the professional opportunities for development.

\& Annual procedure for assessing the staff as an important tool for assessing individual performance, a base for contract renewal, for progress and promotion.

\& ISO standards for policies and procedures to be monitored by internal trained auditing teams, yearly, and approved by the external agencies for ISO evaluations.

\& University finances monitored from the internal auditor as well as an external auditor internationally accredited.

\& Utilization and development of objects and resources should be planed and monitored via yearly self assessment and the process of planning, with the priorities linked to the strategic plan.

\& The satisfaction of students and staff with the services provided should be measured through an assessment carried by students and staff filling the surveys. limited to:

In order to develop a culture of quality the university must use a set of external assessment tools including but not

$\Rightarrow$ European Universities Association (EUA) which ensures an objective external assessment for a four year cycle.

$\Rightarrow$ The quality sample which is provided at least twice a year and from it to carry verification and assessment with recommendation for improvement and follow up.

$\Rightarrow$ Ministry of Education, Science and Technology and other relevant state bodies such as the Accreditation and 
Assessment Agency should increase the responsibilities and carry external auditing and assessment to license new programs and reapprove existing ones.

$\Rightarrow$ External assessment of the study programs must conduct the review of the programs for a 3-5yearly cycle in order to provide analysis and recommendation to the faculties/academic unit and support their development.

$\Rightarrow$ ISO external standards should be applied with a yearly ri- validation in order to verify the effectiveness of the policies and procedures.

It is also important that the document in question, process and the responsible structure for quality management assurance to be reviewed on yearly basis from the Committee for quality management assurance and the quality assurance teams of the faculties/departments. Haxhi Zeka University should definitely create a clear organizational structure in the following manner:

\& A central office for QA with specialized staff or;

\& A quality assurance manager who assigns and manages a network of quality assurance with all university units or;

\& The functions of quality assurance can be included in various organizational units of the institution.

\section{The Role of the Manager in Quality Management Assurance}

The term 'process of the quality management assurance' or the framework of quality management assurance is usually referred to an official system of management that is used to empower a provider of Higher Education. In fact, through this process are determined the expectations, the working standards are aimed to be increased and it is assumed to guarantee that everything is done properly. An adequate quality assurance system is usually initiated by determine the expectations (from several actors) from which a comparison with current performance is made. This could be the self assessment or external assessment. This assessment is followed by planning the actions (to improve) and monitoring the change brought by the said actions. A system determines the manner how the quality development is managed, explains how to collect evidences and how to assess the service quality in order to analyze the needs and set the goals for quality development. The systems of quality assurance referred to: the internal processes by making the systems operational, which offer performance and respond to questions such as: Are we doing it properly? and external spaces for example the goals, values and expectations (results) [Manual for Internal Systems for quality assurance in the institutions of Higher Education- published by the Agency for Accreditation of the Higher Education in the Republic of Albania, taken from internet on13..11.2013 at 23.56

http://www.albranking.com/web/dokumente/manuale/Manual_per\%20NJBSC_30\%20tetor_2012\%20(APAAL).pdf]

An issue which is merely a part of the academic debate is the issue of what should be the profile of a manager or managers that would have the necessary capacities and skills to bear these complex processes. The profile of such a manager should initially be checked for skills and techniques that would enable a quality management assurance based on processes and results. To be more precise the engagement of the managers must be divided in two main responsibilities:

Managers or owners of the process and

$\rightarrow$ Quality managers. [Manual for Internal Systems for quality assurance in the institutions of Higher Educationpublished by the Agency for Accreditation of the Higher Education in the Republic of Albania, taken from

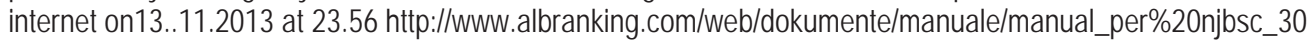
\%20tetor_2012\%20(ap al).pdf]

a) Managers of the process must possess knowledge for all process details and is responsible for the process success for example the students evaluations, teaching and learning processes.

b) The role of the quality manager, the official for the quality assurance, is to measure the effectiveness and efficiency of the process. Furthermore the role of the quality manager is to carry the overall systematic review of the system and its functionality. Before describing the processes there is the need to identify the strategic objectives of the university in order to go to the objectives of each unit.

\section{Conclusions}

The main mission of the system for quality management assurance is to foresee the continuous improvement of a Higher Education institution. The continuing improvement process is made possible from the effort and engagement of all parties involved and recommends the empowerment of the participants which can be made through the development of the 
regular personnel activities.

In institutional basis in the Republic of Kosovo it is required for each provider of Higher Education to establish at least one unit for internal quality assurance (UIQA) in order to continuously improve the quality of educational requirements. Therefore the role of such a structure is dual: the quality improvement and internationalization. The main functions of the UIQA are those of a quality manager. The Republic of Kosovo has a relatively good legislation which obliges the providers of Higher Education to raise, make operational and structure suitable mechanisms for quality management assurance in their own normative acts. Surely, this process is currently challenging due to the fact that these institutions, despite the progress they have made in the formal documentations and plans, have not truly done anything in increasing the culture and implementation of a university based on knowledge and quality.

Truly, even "Haxhi Zeka" University is amongst these institutions that have shown no readiness in its plans to seriously challenge itself with creating mechanisms to assure quality. This is precisely so due to the fact that continues improvement is an intervention to prevent worsening a process and increase quality. To continuously improve the quality of an institution in general and each process specifically, it is strongly recommended to approach with additional improvements in a continuing process. The continuing process of improvement is known as Demings cycle P-D-C-A. The four initial steps of the cycle are: $\mathrm{P}$ (Planning)-data collection to identify and determine issues/problems that need to be improved and to identify ways to achieve that. D (do)-implement the plan by using a preliminary test, a group of tests. $C$ (check)- analyzing results to see if there is a match between the initial goals and what has truly been achieved; make improvements if necessary and $\mathrm{A}$ (action)- based on results from the step $\mathrm{C}$ for checking, acting upon the plan in a full scale or further accomplishing work by starting with $\mathrm{P}$ (planning).

"Haxhi Zeka" University must issue a document, respectively a normative academic strategy that determines the structures and the responsibilities of the office-center which is authorized to do the quality management assurance. One of the most important issues remains the role of the manager/s who would separately assure and then manage the quality in the university. All this thou will remain entirely unsuccessful if not followed with planning and allocation of budgetary means since every serious engagement bears the budgetary costs.

\section{References}

MEST Strategy on Higher Education 2005 - 2015, Prishtina 2004

Manual for Internal Systems for quality assurance in the institutions of Higher Education- published by the Agency for Accreditation of the Higher Education in the Republic of Albania, taken from internet on 13..11.2013 at 23.56 http://www.albranking.com/web/dokumente/manuale/Manual_per\%20NJBSC_30\%20tetor_2012\%20(APAAL).pdf

Manual for Drafting the Framework for Quality in Higher Education, drafted via the project for Support and Development of the Structures for Quality Assurance in the Private Institutions for Higher Education in Kosovo-Bucharest, Cork, Gratz, Prishtina, Salzburg, 2011

European qualification framework for lifelong learning -published by the European Community Commission / Brussels, 8.7.2005 - SEC (2005) 957Law No.04/L-037 On Higher Education In The Republic Kosovo,

MEST Administrative Order, No. 02/2013 on the Accreditations of the Institutions of Higher Education in the Republic of Kosovo

MEST Administrative Order No. 14/2013 on the Teachers Performance Evaluations 